The Journal of

\title{
Thoracic and Cardiovascular Surgery
}

Vol 130, No. 5, November 2005

\section{Coming next month: CME online}

Andrew S. Wechsler, MD, Editor

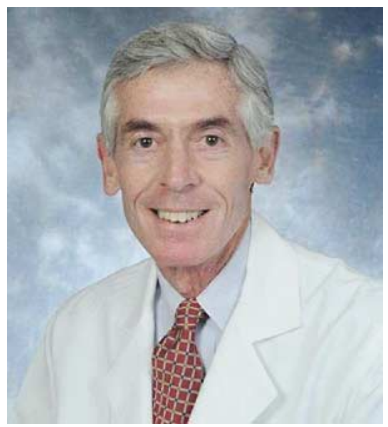

$\mathrm{T}$

he American Association for Thoracic Surgery (AATS), through its publication, The Journal of Thoracic and Cardiovascular Surgery, is instituting a program that will allow subscribers to acquire Continuing Medical Education (CME) credits by taking an examination online that is linked to articles appearing in the Journal. This new service to subscribers will begin with the December issue. The AATS is taking this step after discussions with The American Board of Thoracic Surgery, which has confirmed that it will allow Category 1 credits for such CME activity to count toward recertification. Look for further details in the December issue of the Journal, where the mechanisms for taking the courses and obtaining CME credits are reviewed in greater detail.

From the Department of Cardiothoracic Surgery, Drexel University College of Medicine, Philadelphia, Pa

Received for publication Sept 6, 2005; accepted for publication Sept 7, 2005

Address for reprints: Andrew S. Wechsler, MD, Department of Cardiothoracic Surgery, Drexel University College of Medicine, 230 North Broad St, Mail Stop 111, Philadelphia, PA 19102-1192 (E-mail: Andrew.Wechsler@DrexelMed.edu).

J Thorac Cardiovasc Surg 2005;130:1235

$0022-5223 / \$ 30.00$

Copyright (C) 2005 by The American Association for Thoracic Surgery

doi:10.1016/j.jtcvs.2005.09.001 